\title{
Daniel Compère, Les Romans populaires
}

\section{Eloisa Del Giudice}

\section{(2) OpenEdition}

\section{Journals}

\section{Édition électronique}

URL : http://journals.openedition.org/studifrancesi/2170

DOI : 10.4000/studifrancesi.2170

ISSN : 2427-5856

\section{Éditeur}

Rosenberg \& Sellier

\section{Édition imprimée}

Date de publication : 1 avril 2014

Pagination : 148-149

ISSN : 0039-2944

\section{Référence électronique}

Eloisa Del Giudice, " Daniel Compère, Les Romans populaires », Studi Francesi [En ligne], 172 (LVIII | I) |

2014, mis en ligne le 01 avril 2014, consulté le 18 septembre 2020. URL : http://

journals.openedition.org/studifrancesi/2170; DOI : https://doi.org/10.4000/studifrancesi.2170

Ce document a été généré automatiquement le 18 septembre 2020.

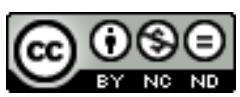

Studi Francesi è distribuita con Licenza Creative Commons Attribuzione - Non commerciale - Non opere derivate 4.0 Internazionale. 


\title{
Daniel Compère, Les Romans populaires
}

\author{
Eloisa Del Giudice
}

\section{RÉFÉRENCE}

DANIEL COMPÈRE, Les Romans populaires, Paris, Presses Sorbonne Nouvelle, 2011, pp. 140.

1 Dans un ouvrage succinct et maniable, Daniel Compère affronte la tâche à la fois lourde et délicate qu'est l'analyse du (des) roman(s) populaire(s) en tant que phénomène global: littéraire, historique, éditorial et sociologique. Conscient des ramifications et des dérives que peut engendrer l'étude d'un domaine aussi vaste et mouvant, l'auteur concentre son attention sur le roman populaire français, depuis ses origines - vers 1820 - jusqu'à nos jours.

2 L'analyse ne peut que commencer par la définition même de «roman populaire». Pour tenter de dépasser les contradictions et les confusions qui depuis toujours rendent cette nébuleuse littéraire particulièrement difficile à appréhender, Compère propose la définition suivante: «Un roman populaire est une œuvre de fiction qui, dès sa publication, vise un large public, mais qui ne sera pas nécessairement reconnue comme littérature légitime» (p. 13). Cette définition permet à l'auteur d'articuler avec grande clarté le phénomène du roman populaire dans sa globalité. Premièrement, la littérature populaire est étudiée sous un angle historique: née de la tradition du colportage, elle se renforce par la démocratisation de ses supports (journaux, fascicules et livres). La petite et moyenne bourgeoisie - qui est le peuple dont on parle quand on parle de «roman populaire» - devenant avide de lectures à la fois distrayantes et pédagogiques, la presse écrite et les maisons d'éditions répondent à l'appel par de nombreux moyens: créations de nouvelles revues et de nouvelles collections à bas prix, essor du romanfeuilleton dans les journaux, vente par livraison, diffusion des cabinets de lecture... La nature "physique» des supports influence ainsi l'évolution des genres du roman populaire: la scansion des parutions dans la presse rythme la structure du récit, se crée 
le phénomène de la sérialité où un même personnage revient au fil de plusieurs romans, le public a le temps matériel d'influencer par ses réactions, positives ou négatives, la continuation du récit, etc.

Dans ce vaste panorama commencent à se dessiner les genres principaux qui constituent l'ensemble «roman populaire», ces genres se regroupant en quatre branches thématiques: l'aventure, l'énigme, le fantastique et l'amour. Dans le premier groupe nous trouvons le roman d'aventures, noyau originel à partir duquel de nombreux autres genres sont nés et se sont peu à peu autonomisés, caractérisé par un fort dépaysement spatio-temporel et de nombreux rebondissements narratifs; le roman historique né du mouvement romantique et qui partage avec le roman d'aventures l'attention à la pédagogie; le western; le roman d'espionnage, qui se développe particulièrement avec les Grandes Guerres et la Guerre froide; la science-fiction. La branche de l'énigme rassemble ces romans dont le noyau central n'est pas une quête (comme c'est le cas dans les romans d'aventures) mais une énigme, souvent de nature criminelle: il y a les romans policiers, où la logique et la loi tiennent une place centrale; le roman noir, caractérisé par un ancrage plus fort dans les sous-bois urbains et par une représentation plus frontale de la violence; le roman d'aventures policières, mélange de genres où la violence tient un rôle dominant. Dans la catégorie des récits fantastiques on distingue le fantastique populaire, l'horreur et la fantasy. Enfin, dans le très vaste domaine des romans à caractère amoureux, on retrouve le roman sentimental, le mélo et les romans érotiques / pornographiques.

4 Pour clore son analyse, l'auteur affronte le rapport entre la littérature populaire et les diverses institutions qui l'ont soit approchée soit éloignée du public. D'une part, est étudié le rôle d'intermédiaires que jouent dans la publication et dans la diffusion de la littérature populaire les éditeurs et les bibliothécaires; d'autre part, est analysé le rapport délicat qui relie (ou plutôt sépare) cette même littérature des grandes institutions culturelles (académie, critique littéraire, universités...).

5 Avec son étude, Daniel Compère fournit un outil simple et valable pour quiconque - de l'étudiant en littérature au simple passionné - veut s'engager dans l'exploration de la littérature populaire: conçu presque plus comme un guide que tel un essai (on apprécie les bibliographies thématiques très riches qui ponctuent chaque chapitre du livre et ouvrent de perspectives plus vastes au lecteur), Les Romans populaires indique de façon succincte toute les grandes questions relatives au roman populaire, et notamment les épineuses ou les irrésolues. N'éclairant que le début de ce chemin d'étude, l'auteur souhaite créer ainsi de «nouvelles vocations» de recherche qui puissent à la fois enrichir et ennoblir ce domaine littéraire aussi vaste que mal jugé. 